\title{
Rapid Detection of $\beta$-Lactamase-Producing Bacteria Using the Integrated Comprehensive Droplet Digital Detection (IC 3D) System
}

\author{
Yiyan Li ${ }^{1,+}$, Hemanth Cherukury ${ }^{2,3,+}$, Louai Labanieh ${ }^{4}$, Weian Zhao ${ }^{2,3,5,6,7,8}$ and \\ Dong-Ku Kang 9,10,*(D) \\ 1 Department of Physics and Engineering, Fort Lewis College, Durango, CO 81301, USA; yli@fortlewis.edu \\ 2 Department of Pharmaceutical Sciences, University of California Irvine, Irvine, CA 92697, USA; \\ hcheruku@uci.edu (H.C.); weianz@uci.edu (W.Z.) \\ 3 Sue and Bill Gross Stem Cell Research Center, University of California Irvine, Irvine, CA 92697, USA \\ 4 Department of Bioengineering, Stanford University, Stanford, CA 94305, USA; llabanie@stanford.edu \\ 5 Chao Family Comprehensive Cancer Center, University of California Irvine, Irvine, CA 92697, USA \\ 6 Edwards Life Sciences Center for Advanced Cardiovascular Technology, University of California Irvine, \\ Irvine, CA 92697, USA \\ 7 Department of Biomedical Engineering, University of California Irvine, Irvine, CA 92697, USA \\ 8 Department of Biological Chemistry, University of California Irvine, Irvine, CA 92697, USA \\ 9 Department of Chemistry, Incheon National University, Incheon 22012, Korea \\ 10 Research Institute of Basic Sciences, Incheon National University, Incheon 22012, Korea \\ * Correspondence: dkkang@inu.ac.kr; Tel.: +82-32-835-8094 \\ + These authors contributed equally to this work.
}

Received: 24 July 2020; Accepted: 17 August 2020; Published: 19 August 2020

check for updates

\begin{abstract}
Antibiotic-resistant bacteria have emerged as an imminent global threat. The lack of rapid and sensitive diagnostic techniques leaves health care providers with inadequate resources for guiding therapy and risks the lives of patients. The traditional plate culturing methods for identifying antibiotic-resistant bacteria is laborious and time-consuming. Bulk PCR (Polymerase Chain Reaction) and qPCR are limited by poor detection sensitivity, which is critical for the early-stage detection of bloodstream infections. In this study, we introduce a technique for detecting $\beta$-lactamase-producing bacteria at single-cell sensitivity based on a commercial $\beta$-lactamase sensor (Fluorocillin), droplet microfluidics, and a custom 3D particle counter. Bacteria-containing samples were encapsulated within picoliter-sized droplets at the single-cell level and cultured within water-in-oil droplets containing antibiotics and the Fluorocillin sensor. Then, fluorescent droplets were digitally quantified with the 3D particle counter, which is capable of analyzing milliliter-scale volumes of collected droplets within $10 \mathrm{~min}$. The fluorescence signal from single-colony droplets was detectable in less than $5 \mathrm{~h}$, and the 3D scanning was performed in less than $10 \mathrm{~min}$, which was significantly faster than conventional culture-based methods. In this approach, the limit of detection achieved was about 10 bacterial cells per $\mathrm{mL}$ of sample, and the turnaround time from sample to result was less than $6 \mathrm{~h}$. This study demonstrates a promising strategy for the detection of $\beta$-lactamase-producing bacteria using the recently developed IC 3D system.
\end{abstract}

Keywords: IC 3D; droplet microfluidics; digital quantification

\section{Introduction}

Due to the use of $\beta$-lactam antibiotics in medicine, agriculture, and veterinary medicine, bacteria have evolved to survive in the presence of antibiotics by mutating and encoding extended-spectrum 
$\beta$-lactamases (ESBLs). The evolution of ESBLs has been faster than the cycle of developing new drugs, which leads to a high failure rate of treating infections caused by ESBLs. The situation is especially dire when bacteria enter the bloodstream and cause bloodstream infections (BSI). Without proper treatment, BSI can lead to sepsis and result in a very high mortality rate. An estimated $20 \%$ of all annual deaths are caused by complications due to sepsis, making up nearly $50 \%$ of all deaths in the hospital [1]. Nearly 1 million individuals are hospitalized due to sepsis annually in the US alone with at least 30,000 of those patients dying in the hospital, and the numbers are rising every year [2]. The high mortality rate of sepsis can be attributed to the lack of rapid diagnostics tools to direct the proper administration of antibiotics by healthcare providers. The current gold standard for bacterial infection diagnosis remains the 100-year-old plate culture method, which can take up to 5 days to grow the pathogen to detectable levels, and even longer for confirmation of a negative result [3]. Until the results of the culture are confirmed, physicians are generally directed to administer a cocktail of broad-spectrum antibiotics in the hopes that one or more of the antibiotics will be effective in curbing the infection $[4,5]$. However, this empirical treatment is ineffective in up to $50 \%$ of patients [6]. Compounding the issue is the high incidence of drug-resistant bacteria and especially multi-drug resistant (MDR) bacteria, the prevalence of which is further increased by nonspecific broad-spectrum antibiotic administration $[7,8]$. Therefore, there is an urgent need for a rapid diagnostic test that can give sample-to-result in less than $24 \mathrm{~h}$.

More recently, nano- and micro-based systems have been developed such as Droplet Digital PCR (ddPCR) [9-11], which involves the partitioning of the sample into thousands or millions of droplets, followed by separate PCR reactions occurring within each individual droplet. The number of DNA copies contained in each droplet can be predicted by the Poisson distribution [12]. Samples with low target concentrations can be partitioned into millions of nanoliter-sized droplets with a low probability that any droplet will contain more than one target. Once the reaction is complete, the positive droplets will fluoresce, which allows for counting by a flow cytometer to determine the number of positive droplets with single-digit sensitivity. Compared to traditional qPCR, ddPCR can improve detection sensitivity and selectivity but typically is limited to small sample volume ( $\mu \mathrm{Ls})$, which cannot handle the required clinical sample volume (mLs of blood) and throughput, as bacteria in patient samples may be present at single-digit CFU levels. These conventional methods tend to require expensive equipment and complex sample processing steps (e.g., cell lysis, nucleic acid extraction, amplification of signal) to purify and enrich the target, resulting in significant target loss when there are only a low number of targets present in the sample [13].

The majority of molecular diagnostic assays for antibiotic resistance have targeted genetic markers; however, these do not always correlate to the observed phenotype. On the other hand, phenotypic assays such as antibiotic susceptibility testing and $\beta$-lactamase activity assays act as a more direct functional readout for antibiotic resistance $[14,15]$. $\beta$-lactams are historically the most successful antibiotics and account for the majority of antibiotics prescribed today [16]. They work by inhibiting the synthesis of the bacterial cell wall. Resistance to $\beta$-lactams is primarily mediated through enzymes, known as $\beta$-lactamases, which hydrolyze the $\beta$-lactam ring of these antibiotics, rendering them ineffective [17]. Common pathogenic Enterobacteriaceae such as K. pneumoniae and E. coli typically carry extended spectrum $\beta$-lactamase (ESBL) or carbapenem resistance (CRE), and they are among the most prevalent antimicrobial-resistant pathogens $[18,19]$. ESBLs and CREs account for $10-20 \%$ of serious E. coli infections and $20-30 \%$ of Klebsiella infections reported nationally [20]. ESBLs mediate resistance to extended-spectrum $\beta$-lactam antibiotics, including cephalosporins and monobactams. Even worse are the carbapenemases produced by CREs that can hydrolyze almost all $\beta$-lactam antibiotics including carbapenems, which are typically used as the "drug of last resort" to treat severe infections by Gram-negative bacteria [21]. Indeed, the mortality rate of bloodstream infections (BSI) due to CREs is over $50 \%$ [22]. 
We recently reported a technology termed Integrated Comprehensive Droplet Digital Detection (IC 3D), which is capable of analyzing milliliters of droplets within minutes to identify target pathogens (Figure 1) [23-26].
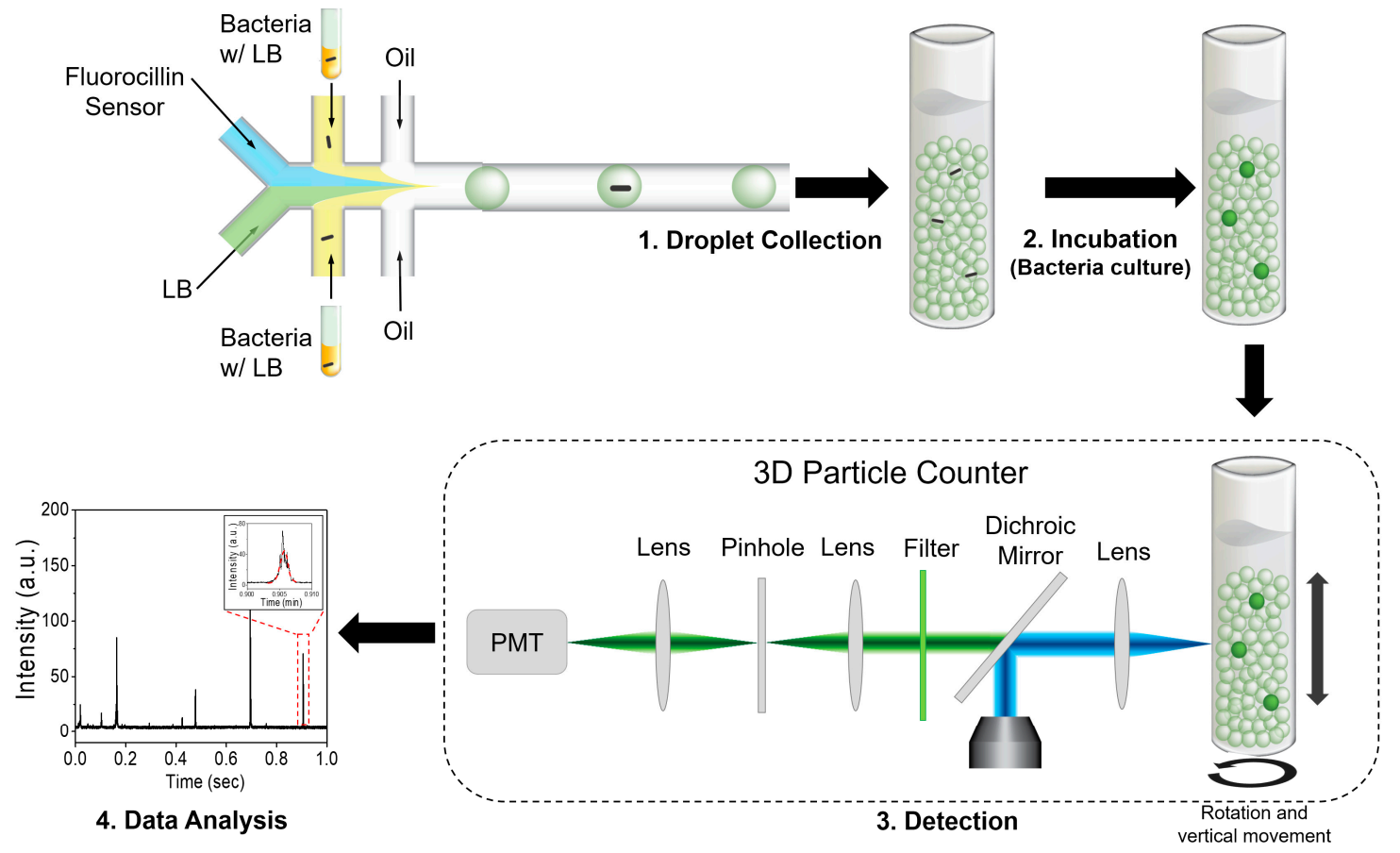

Figure 1. The diagram of the single-bacterium detection using the Integrated Comprehensive Droplet Digital Detection (IC 3D) system. The presence of a single bacterium in a microfluidic droplet results in detectable fluorescence when excited by a laser. The IC 3D droplet counter quantifies the positive spikes and reports the bacteria counts in the sample.

Here, we report a phenotypic droplet assay for $\beta$-lactamase-mediated antibiotic resistance. Basically, bacterial cells were encapsulated within $60 \mu \mathrm{m}$ droplets with antibiotics and a fluorescence-producing $\beta$-lactamase sensor. After encapsulation, only antibiotic-resistant bacteria can be grown inside droplets, and fluorescent droplets indicate $\beta$-lactamase production from grown bacteria. This is the first report of the detection and quantification of $\beta$-lactamase-producing bacteria in a relatively large volume of sample $(1 \mathrm{~mL})$ without sample preparation and pre-cultivation using droplet-based microfluidics. In this study, clinically relevant samples were rapidly analyzed in a highly sensitive manner by integrating phenotypic assay with IC 3D technology. This phenotypic approach for the monitoring of antibiotic-resistant bacteria in droplets avoids the pitfalls and expense of molecular-based assays while being significantly faster than traditional culture-based methods.

\section{Materials and Methods}

\subsection{Bacteria Preparation}

The STAR and AD494 strains are engineered ampicillin-resistant Escherichia coli (E. coli) and were provided by Dr. Jianghong Rao (Stanford University). Ampicillin-susceptible Top10 E. coli (Thermo Fisher, Waltham, MA, USA) and Bacillus subtilis (B. subtilis, ATCC ${ }^{\circledR} 82^{\mathrm{TM}}$, ATCC, Manassas, VA, USA) were purchased and the other ampicillin-susceptible K12 E. coli was a kind gift from Dr. Manuela Raffatellu (UC Irvine). De-identified clinically isolated bacteria (\#41 and \#47) were obtained from Dr. Ellena Peterson through the UC Irvine Pathology Research Biorepository. A single colony, freshly grown on an agar plate containing lysogeny broth (LB), was inoculated into $5 \mathrm{~mL}$ of LB and incubated with shaking at $37^{\circ} \mathrm{C}$ for $14 \mathrm{~h}$. Ten (10) $\mu \mathrm{L}$ of this culture was further inoculated in $5 \mathrm{~mL}$ fresh LB 
for $4 \mathrm{~h}$, and the concentration of bacterial cells was determined by the colony-forming unit (CFU) assay using freshly cultured bacterial cells. E. coli $\mathrm{K} 12$ or other E. coli strains were freshly cultured as described above. Then, two mL of cultured cells were serially diluted in 10-fold intervals with LB and divided into two groups: one for stock with $20 \%$ glycerol and the other for the CFU assay. Cell concentrations ranging from the 4 th to the 9 th dilution were then plated onto the agar-LB plates using $100 \mu \mathrm{L}$ of diluted cells. Then, the bacterial suspension was spread evenly over the entire surface of the plate. After drying, the plates were taped to prevent contamination and incubated at $37^{\circ} \mathrm{C}$ overnight or until colonies formed. After the colonies reached a suitable size, they were counted to determine the cell concentration.

\subsection{Synthesis of PFPE-PEG-PFPE Surfactant}

The biocompatible fluorinated surfactant used for droplet generation was synthesized as previously described by Chen et al. [27]. Krytox 157FS (H) (50 g, MW: 5000 g/mol, Dupont, Londonderry, UK) was dissolved in $50 \mathrm{~mL}$ anhydrous HFE-7500 with excess oxalyl chloride (12.5 g, Sigma-Aldrich, Gillingham, UK) and stirred overnight at $85^{\circ} \mathrm{C}$ under argon. The solvent was removed through rotary evaporation and high vacuum. The resulting light-yellow product was mixed with Jeffamine XTJ 501 ( $3.5 \mathrm{~g}$, MW: $900 \mathrm{~g} / \mathrm{mol}$, Sigma-Aldrich, UK) and dissolved in a mixture of $50 \mathrm{~mL}$ HFE-7500 with $50 \mathrm{~mL}$ of anhydrous dichloromethane ( $50 \mathrm{~mL}$, Sigma-Aldrich, UK) at $65^{\circ} \mathrm{C}$ with stirring for 2 days under an argon atmosphere, resulting in a milky white product after rotary evaporation. Insoluble white particles were removed through centrifugation at $8000 \mathrm{rpm}$ for approximately $10 \mathrm{~min}$ and dried using a vacuum desiccator for $24 \mathrm{~h}$. Then, the surfactant was used without any further purification.

\subsection{Fabrication of Droplet-Based Microfluidic Chip and Droplet Generation}

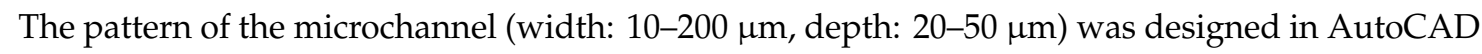
and printed on high-resolution film masks by CAD/Art Services (Bandon, OR, USA). Two aqueous inlets are used to deliver the Fluorocillin sensors and the bacteria sample to the microfluidic channels separately to minimize the reaction before the droplet formation. The channel design was transferred to 4 -inch silicon wafers by the standard photolithography procedure, which follows. The wafers were briefly rinsed with 5\% hydrofluoric acid (Sigma-Aldrich, St. Louis, MO, USA) and deionized (DI) water. Before spin coating (6NPP-LITE, Laurell Technologies Corporation, North Wales, PA, USA), wafers were dehydrated in an oven at $95{ }^{\circ} \mathrm{C}$ for $10 \mathrm{~min}$. Then, negative photoresist (approximately $3 \mathrm{~g}$, SU-8 50, MicroChem, Chestech, UK) was spin-coated (500 rpm for $10 \mathrm{~s}$, then $3000 \mathrm{rpm}$ for $30 \mathrm{~s}$ ) onto the wafer. Then, the SU-8 layer was cured on a hotplate at $65^{\circ} \mathrm{C}$ for $5 \mathrm{~min}$ and at $95^{\circ} \mathrm{C}$ for $30 \mathrm{~min}$. Then, the cured SU-8 layer was exposed to UV radiation $\left(14 \mathrm{~s}, 20 \mathrm{~mW} / \mathrm{cm}^{2}\right.$, AB\&M INC UV Flood Exposure System) through the photomask, and the wafer was subsequently post-baked for $1 \mathrm{~min}$ $\left(65^{\circ} \mathrm{C}\right)$ and $5 \mathrm{~min}\left(95^{\circ} \mathrm{C}\right)$. Unexposed SU-8 was removed by soaking in SU-8 developer for $5 \mathrm{~min}$. Then, the wafer was cleaned using isopropyl alcohol, blow-dried with filtered nitrogen gas, and silanized with perfluorooctyl-trichlorosilane (Sigma-Aldrich, St. Louis, MO, USA) under vacuum for $3 \mathrm{~h}$.

PDMS (Polydimethylsiloxane, Sylgard 184, Dow Corning, Midland, MI, USA) and its curing agent were mixed in the ratio of 10:1 w/w. The mixture was stirred thoroughly to avoid any uncured PDMS base and followed by a 20-min degassing process in a vacuum chamber. Then, the mixture was poured onto the patterned silicon wafer mold and fully cured in an oven (at least $4 \mathrm{~h}$ at $65^{\circ} \mathrm{C}$ ). The cured PDMS pieces were peeled off from the wafer and bonded to cleaned glass slides following the plasma treatment.

Various concentrations of E. coli $\mathrm{K} 12$ or other strains of bacterial cells were prepared through serial dilution and subsequently spiked in LB. Then, bacterial cell-spiked LB samples were microencapsulated with $2 \mu \mathrm{M}$ Fluorocillin sensor using a droplet microfluidic device. Droplets were collected within $2 \mathrm{~mL}$ cuvettes for incubation at $3{ }^{\circ} \mathrm{C}$ without rotation for $5 \mathrm{~h}$ (Figure 2). 


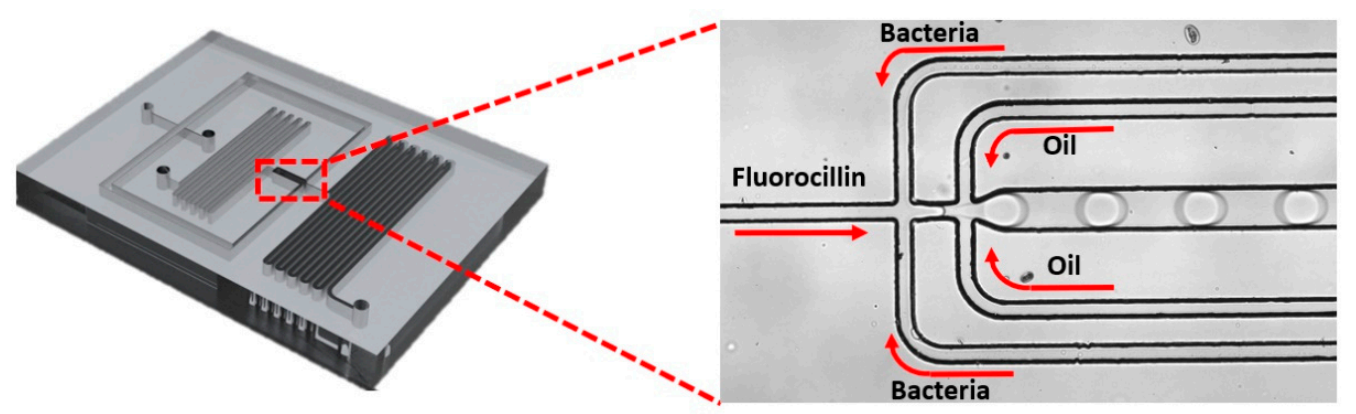

Figure 2. Encapsulation of $\beta$-lactamase-producing bacteria into microdroplets using microfluidic chips.

The engineering oil (HFE-7500) was mixed with the homemade polyethyleneglycol surfactant $(1.8 \% w / w)$ and used as the continuous oil phase for microfluidic droplet generation. HFE-7500 has a low viscosity $\left(0.77\right.$ at $\left.25^{\circ} \mathrm{C}\right)$, a high boiling point $\left(128^{\circ} \mathrm{C}\right)$, and a high density $\left(1614 \mathrm{~kg} / \mathrm{m}^{3}\right)$, which makes it a good candidate for generating microfluidic droplets. The surfactant used in this study has been used with the HFE-7500 oil to stabilize the emulsion and prevent the droplets from coalescing even at $100{ }^{\circ} \mathrm{C}$. The oil and the aqueous phase (Fluorocillin sensor and bacteria culture) were injected into the microfluidic device through syringes and tubing by the PHD 2000 syringe pumps (Harvard Apparatus). The flow rate was limited in the 0.5 to $5 \mu \mathrm{L} \mathrm{min}^{-1}$ range.

\subsection{Identification of $\beta$-Lactamase Production in Bulk}

The fluorescence-based analysis of $\beta$-lactamase production with Fluorocillin sensor (Fluorocillin ${ }^{\mathrm{TM}}$ Green $\beta$-Lactamase Substrates, Invitrogen, Carlsbad, CA, USA), as shown in Figure 3, was performed using a fluorescence microplate reader (Synergy HT, Biotek, Winooski, VT, USA) with an excitation wavelength of $488 \mathrm{~nm}$ and an emission wavelength of $520 \mathrm{~nm}$. To initiate the reaction in the microplate reader, $5 \mu \mathrm{L}$ of a concentration stored-stock sample $\left(1 \times 10^{9}\right.$ or different number of bacterial cells) and $25 \mu \mathrm{L}$ of $2 \times \mathrm{LB}$ were mixed in the microwell plate and $10 \mu \mathrm{L}$ of $\mathrm{H}_{2} \mathrm{O}$ was added to adjust the total volume up to $50 \mu \mathrm{L}$.

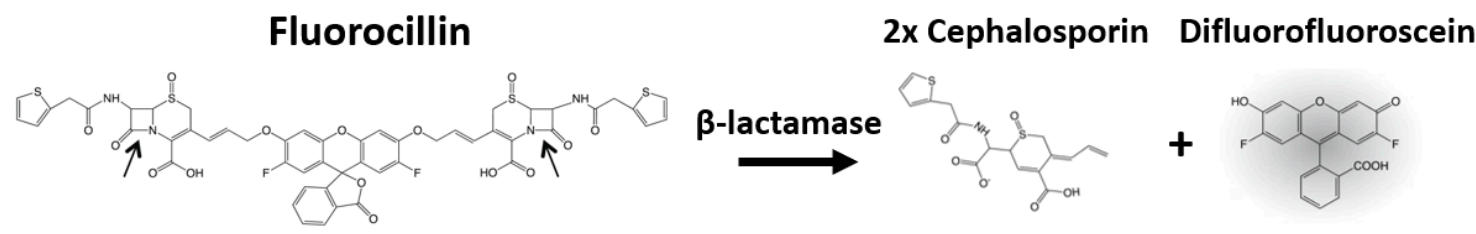

Figure 3. The detection mechanism of bacterial $\beta$-lactamase using Fluorocillin.

Microwell plates were placed into a microplate reader and the fluorescence intensity was monitored at 3 min intervals continuously following the addition of $10 \mu \mathrm{L}$ of $20 \mu \mathrm{M}$ Fluorocilliin sensor into each well. The fluorescence intensity was recorded for $120 \mathrm{~min}$. All the experiments were performed in triplicate.

\subsection{Fluorescence Detection Using the IC 3D System}

The 3D particle counter is the core instrument in the IC 3D system (Figure 1). The 3D particle counter was developed by Dr. Gratton and colleagues at UC-Irvine. The particle counter consists of a narrow beam laser and a dichroic mirror to reflect the laser beam to the sample through an objective lens. The fluorescence emission from the sample is collected by the same objective lens and passes the dichroic mirror, a bandpass filter, and finally reaches the PMT (Photomultiplier tube). The PMT outputs analog electrical signals to a trans-impedance amplifier (TIA), which is followed by a digitizer within the instrument's box. The digital signal is sent to a desktop through a USB cable for data 
analysis. The 3D particle counter can robustly and accurately detect single-fluorescent particles from milliliter volumes within minutes $[28,29]$.

Droplets containing bacterial cells in LB and $2 \mu \mathrm{M}$ Fluorocillin sensors were collected in a cuvette following droplet generation, and droplets were incubated at $37^{\circ} \mathrm{C}$ for $5 \mathrm{~h}$ for the cultivation. Then, $100 \mu \mathrm{L}$ of the generated droplets were mixed with $1.9 \mathrm{~mL}$ of background droplets (pre-made LB droplets that contain $2 \mu \mathrm{M}$ Fluorocillin without any bacteria) in a cleaned cuvette and followed by the $37^{\circ} \mathrm{C}$ incubation. Following incubation, $2 \mathrm{~mL}$ of droplets were analyzed for $3-10 \mathrm{~min}$ in the 3D particle counter. The 3D particle counter was set to rotate at $400 \mathrm{rpm}$ horizontally and move $10 \mathrm{~mm} \mathrm{~s}^{-1}$ vertically during the scanning operation. The time-domain fluorescence signals were collected by the PMT and converted to voltage signals for analysis. The collected voltage intensity waveforms were analyzed with a pattern-recognition filter in software (SimFCS, Laboratory for Fluorescence Dynamics, UC-Irvine, Irvine, CA, USA). The pattern-recognition software has an algorithm to differentiate the positive waveforms from noisy spikes based on the information of fluorescence intensity, cuvette rotation speed, and droplet size given by the users. The concentration of bacteria was determined by fitting the positive counts into a counts-concentration curve that was previously created using standard concentration samples.

\section{Results}

\subsection{Detection of $\beta$-Lactamase-Producing Bacteria in a Bulk Assay}

The functionality of the Fluorocillin sensor was verified in terms of the detection of $\beta$-lactamase-production from bacteria with the 96-well microplate reader. Genetically engineered ampicillin-resistant Escherichia coli (E. coli), the STAR and the AD494 strains, produce $\beta$-lactamase and were used as a known positive control. The fluorescence intensity was generated from the $\beta$-lactamase-initiated cleavage of Fluorocillin, which was saturated for $30 \mathrm{~min}$ after both STAR and AD494 strains were exposed to the substrate (Figure 4a). In this study, two types of clinical isolates were also tested, and strong fluorescence intensity was observed with clinical isolate 7 , which is the ampicillin-resistant strain (Figure 4b), but the ampicillin-susceptible strain (Clinical Isolate 1) showed very weak fluorescence intensity. None of the ampicillin-susceptible strains (Top10, K12, Bacillus subtillis, and Clinical Isolate 1) showed any strong fluorescence signals.
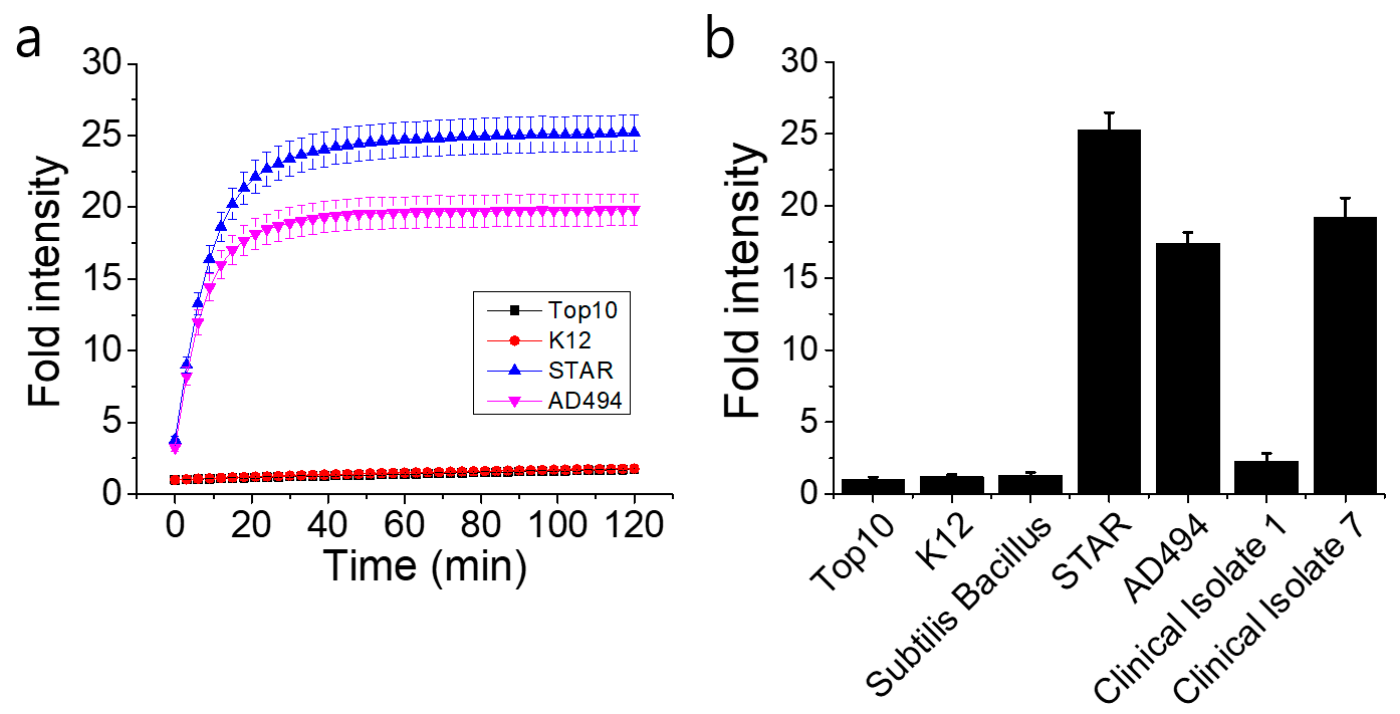

Figure 4. Fluorescence intensity collected by a 96-well microplate reader showed that the $\beta$-lactamaseproducing bacteria were detected by the Fluorocillin sensor. (a) The STAR and the AD494 strains were E. coli engineered with ampicillin resistance, while K12 and Top10 were ampicillin-susceptible E. coli. (b) Fluorescence intensity of all the bacteria selected for this experiment. 
In this experiment, $1 \times 10^{9}$ bacterial cells were loaded in each well of a 96-well plate in Figure 4, and the high number of bacterial cells produced enough $\beta$-lactamase that could reach a plateau of fluorescence intensity within $30 \mathrm{~min}$. To verify the limit of detection for the $\beta$-lactamase-producing bacteria with Fluorocillin in a bulk assay, STAR strains were serially diluted, and fluorescence intensity was monitored for $120 \mathrm{~min}$ at room temperature (Figure 5). For every 10 -fold concentration increase, the signal intensity and the response time showed significant differences (Figure 5a). The sample with the highest bacterial concentration showed the strongest signal intensity and saturated sooner. Consistent with the data in Figure 4, the $10^{7}$ samples showed a saturated fluorescence signal $30 \mathrm{~min}$ after the bacteria were exposed to the sensor. The sensitivity per well (limit of detection) was around $1 \times 10^{4}$ cells per well.
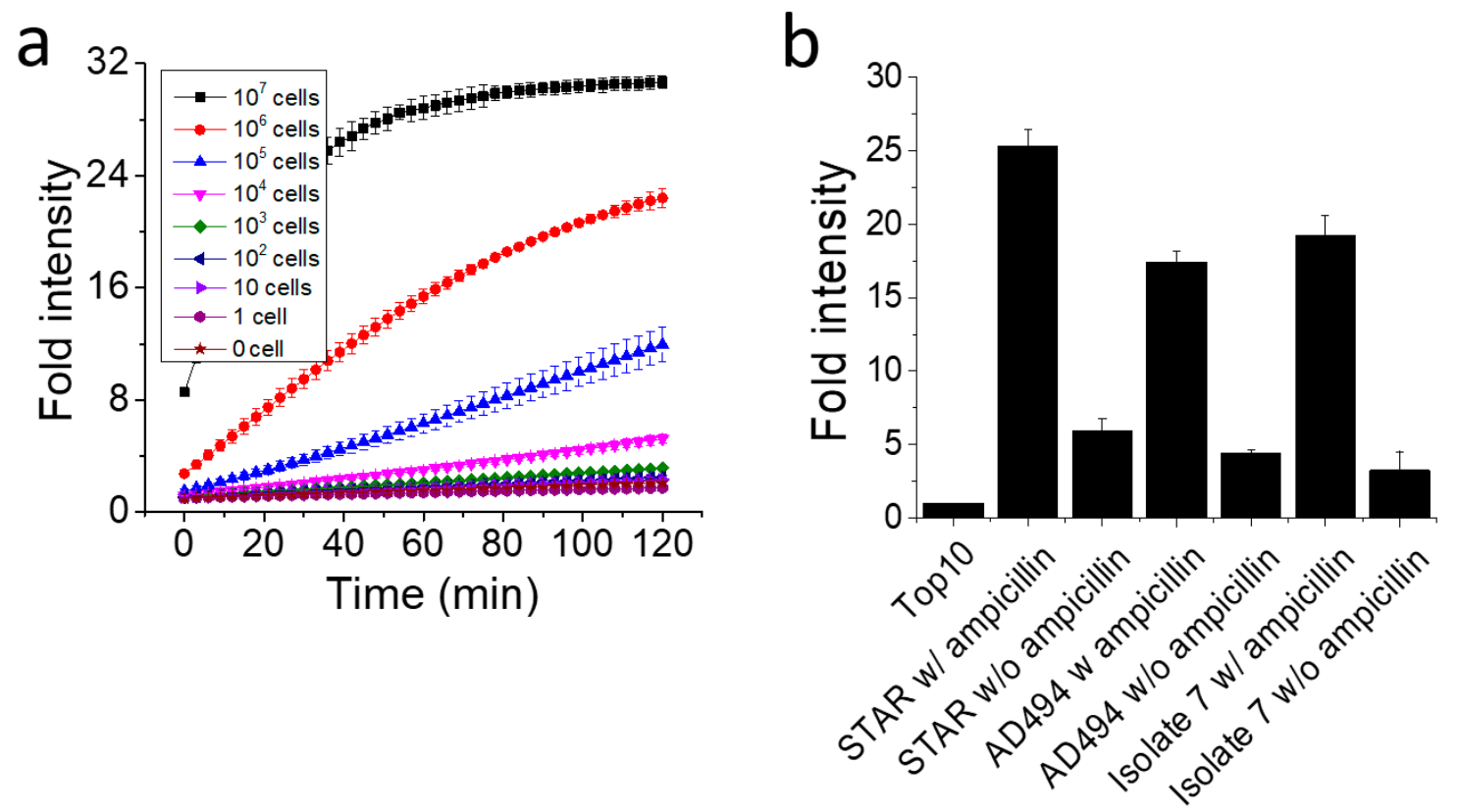

Figure 5. The effect of the bacteria concentration and the presence of ampicillin on the signal intensity. (a) The sensitivity of the Fluorocillin in the bulk assay (STAR strain). (b) Bacterial cells were cultured with or without ampicillin.

The presence of ampicillin in the culture also had a positive impact on enhancing the signal intensity (Figure 5b). Three different bacteria strains were pre-cultured with or without ampicillin to investigate the difference of $\beta$-lactamase production. Each strain was loaded at a cell number of $1 \times 10^{7}$, and fluorescence intensity was monitored after $120 \mathrm{~min}$, with the Top10 ampicillin-susceptible strain serving as a negative control. As shown in Figure $5 b$, ampicillin co-culture increased $\beta$-lactamase production because it modulates the capacity of $\beta$-lactamase production, and fluorescence intensity was identified as 4.35, 4.04 and 5.71-fold higher in the STAR, AD494, and isolate 7 strains, respectively.

$\beta$-lactamase is synthesized inside bacteria and secreted, which resulted in exposure to the Fluorocillin sensor. It was believed that bacterial lysis may induce or increase the sensitivity of $\beta$-lactamases detection with Fluorocillin. To investigate the effect of cell lysis, Fluorocillin and $1 \times 10^{6}$ bacterial cells were incubated with or without lysozyme (Figure 6). Once bacterial cells were lysed with lysozyme, fluorescence intensity saturated more quickly compared to non-lysed cells, using the AD494 strain for the comparison. However, the STAR cell line only showed minor improvement, while the AD494 cell line showed aggressive improvements at the starting point of the experiment. This result suggests that the cell membrane of STAR stain may be more resistant against lysozyme. 
a

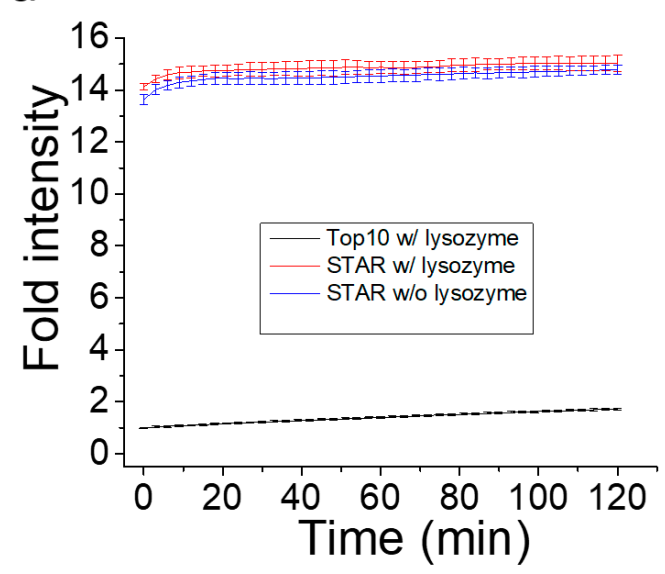

b

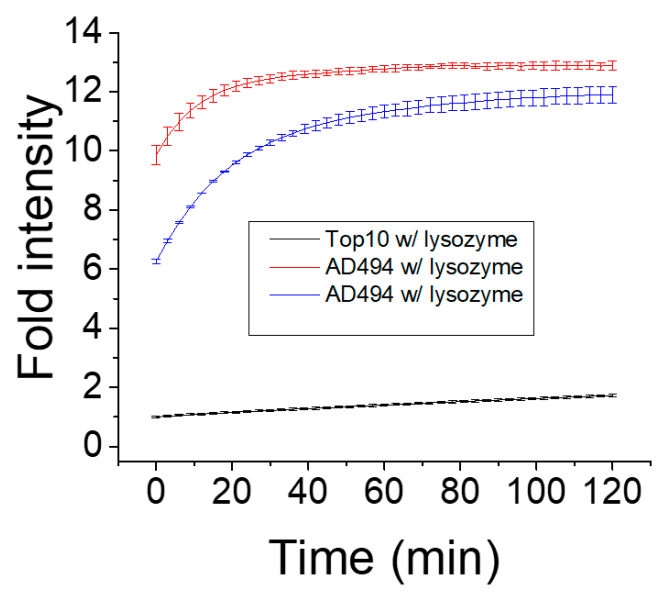

Figure 6. STAR cell line produce more/or active $\beta$-lactamase for Fluorocillin sensor. (a) $\beta$-lactamase activity in STAR strain (a) and AD494 strain (b).

\subsection{Identification of $\beta$-Lactamase-Producing Bacteria with Droplet-Based Microfluidics}

Since each droplet can serve as an isolated bacterial culture, bacterial cells and the Fluorocillin sensor were co-encapsulated within microdroplets using a droplet-based microfluidic device, as shown in Figure 2. To ensure that the reaction verified in the bulk study can be repeated in droplets, bacterial cells were cultured in bulk with ampicillin-containing LB, and a relatively high number of bacterial cells $\left(2 \times 10^{9}\right.$ bacterial cells per $\left.\mathrm{mL}\right)$ were used for encapsulation within $50 \mu \mathrm{m}$ in diameter droplets. Based on the calculation, the volume of the droplets is approximately $65 \mathrm{pL}$ in volume, and 65 bacterial cells were encapsulated per droplet. The resistant strains AD494 and STAR showed strong fluorescence under the fluorescent microscope (Figure 7) and fluorescence intensity among different droplets varied, which may be caused by the deviations of bacterial numbers being captured by every individual droplet during droplet generation. The ampicillin-susceptible strains did not show any significant signals but only some weak background noise from the unreacted Fluorocillin.

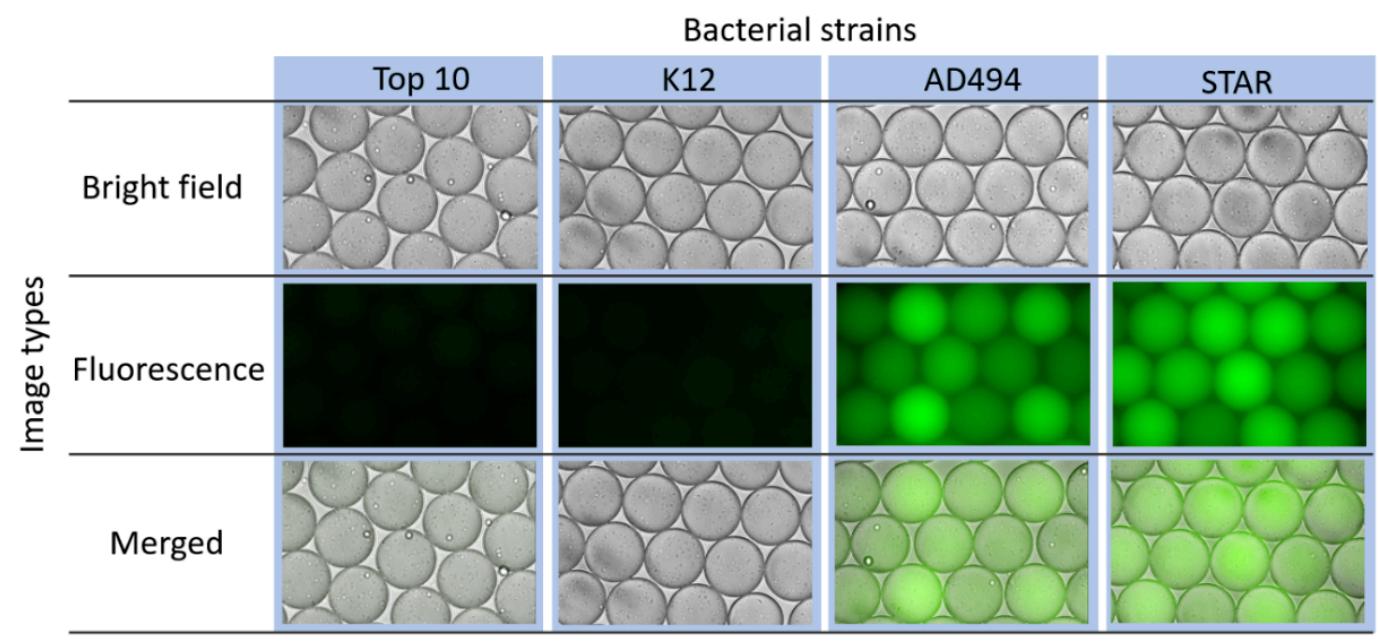

Figure 7. $\beta$-lactamase-producing bacteria showed fluorescence signals in microfluidic droplets.

To determine if bacteria-containing droplets can be detected sooner by culturing in droplets instead of in a traditional liquid culture, we next encapsulated bacteria at the single-cell level in ampicillin-containing media along with the Fluorocillin sensor (Figure 8). Bacteria were cultured from frozen stock and then diluted to a level that ensures only a single bacterium was present in a positive droplet according to the Poisson distribution, such that droplets contained only one or zero 
bacteria [19]. Then, bacteria were cultured in droplets at $37^{\circ} \mathrm{C}$ for $5 \mathrm{~h}$ and imaged by fluorescence microscopy. A single bacterial colony that developed from a single bacterium in a positive droplet was shown in the supplementary video file (S1_Droplet_Single_Colony.mp4).

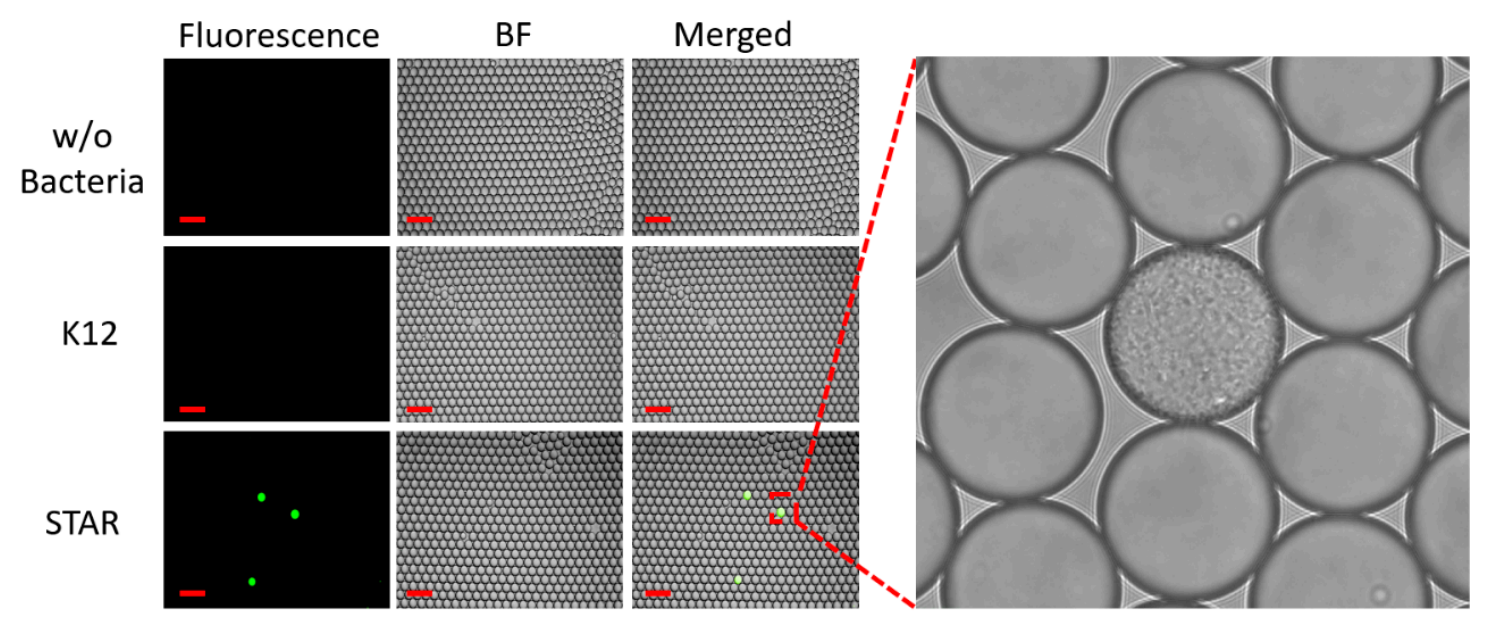

Figure 8. The single-cell culture within droplets to monitor ampicillin-resistant bacteria.

A zoomed-in image shows that one of the positive droplets is filled with bacteria amplified from a single bacterium (Figure 8). Only the ampicillin-resistant bacteria strains grew in the droplets and reacted with the Fluorocillin sensor, resulting in a strong fluorescence signal after the 5-h culture. No fluorescent droplets were seen in the no-bacteria control and susceptible samples (K12).

In optimal conditions, E. coli divides roughly every $20 \mathrm{~min}$, and so after $5 \mathrm{~h}$, there are expected to be 32,768 bacteria formed from a single bacterium in a droplet. Signals are detectable under a fluorescent microscope after $5 \mathrm{~h}$ of culturing at $37^{\circ} \mathrm{C}$ (Figure 9). The optical detector of the microscope is a CMOS (Complementary metal-oxide-semiconductor) camera array that converts the green fluorescent emission into a photocurrent. The PMT in the IC 3D system was more sensitive than the CMOS camera found in commercial microscopes. Therefore, we expected that a 5-h culture will give a strong enough fluorescent signal for detection by the IC 3D system.
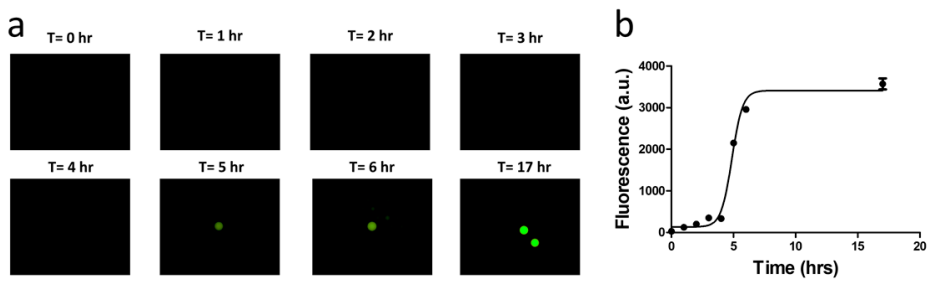

Figure 9. A time-course study of the fluorescent signal intensity of the single-bacterium droplets. (a) Microscopic images of the fluorescent droplet. (b) Fluorescence intensity of droplet.

The signal intensity of the single-bacterium droplets is a function of time of culturing (Figure 9). As bacteria numbers increase within a single droplet, the fluorescence signal rises until the Fluorocillin sensor is depleted. Detectable signals were observed after $5 \mathrm{~h}$; however, the signal intensity increased by $6 \mathrm{~h}$ and saturated at $10 \mathrm{~h}$ of culturing. That said, $5 \mathrm{~h}$ of culture is sufficient for detection by the IC 3D system or a commercial fluorescent microscope.

\subsection{Detection of Clinically Isolated Bacteria Using IC 3D System}

Finally, clinically isolated bacteria were identified with the Fluorocillin sensor using a conventional plate reader-based assay (Figure 10a) and IC 3D (Figure 10b). As shown in Figure 10a, ampicillin-resistant bacteria isolates (isolate 2, 3, 4, 5, and 7) were identified with bulk assay when 
$1 \times 10^{9}$ bacterial cells were incubated with Fluorocillin for $30 \mathrm{~min}$, and isolate 7 was considered to produce the highest amount of $\beta$-lactamase according to highest fluorescence intensity. Isolates 1, 6, 8, and 9 did not show significant fluorescence intensity, and commercial $\beta$-lactamase protein was used as a positive control to be compared to the $\beta$-lactamase-producing isolate groups.
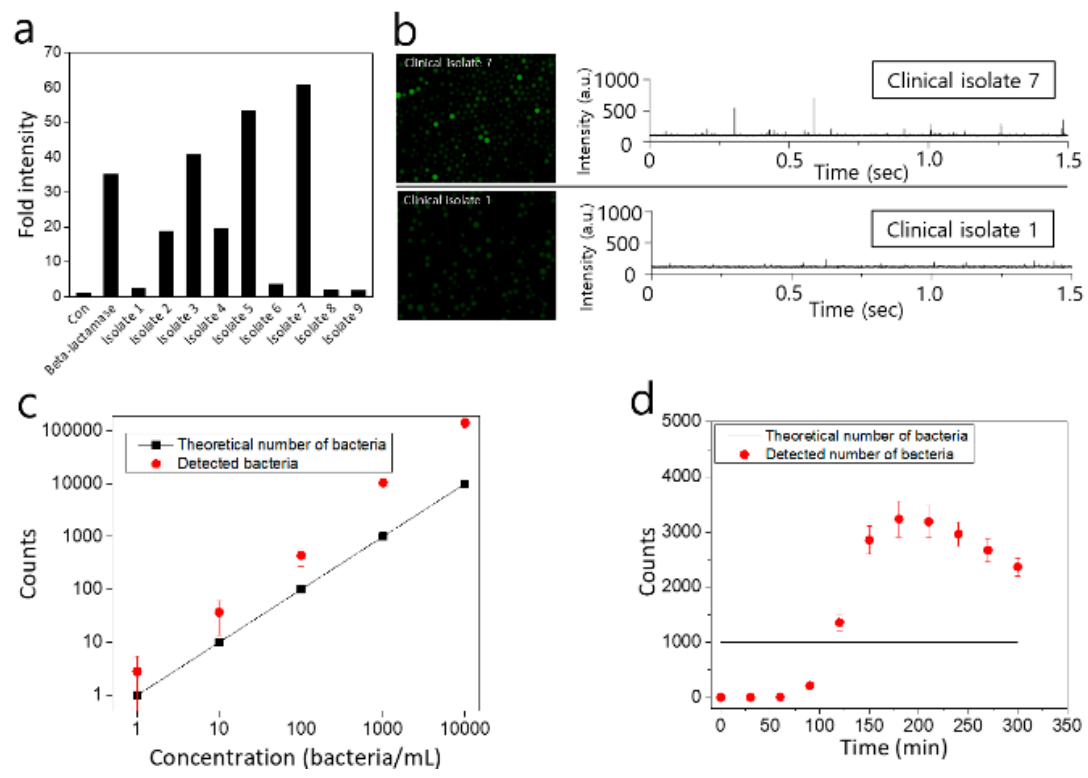

Figure 10. Detection of clinically isolated $\beta$-lactamase-producing bacteria with conventional well plate-based assay (a) or IC 3D (b). (c) Bacteria counts of $\beta$-lactamase-producing bacteria provided by the IC 3D fluorescence particle counter are compared with the theoretical number of bacteria. (d) Time-dependent measurement of 1000 STAR cells using IC 3D. The sample was encapsulated and analyzed every $30 \mathrm{~min}$.

Clinical isolates 1 and 7 were encapsulated within droplets (50 $\mu \mathrm{m}$ in diameter) with $2.5 \mu \mathrm{M}$ Fluorocillin, and droplets were collected in a cuvette for the identification of $\beta$-lactamase-producing bacteria with IC 3D. After a $5 \mathrm{~h}$ incubation period at $30^{\circ} \mathrm{C}$, droplets were analyzed by a fluorescent microscope (Figure 10b, left panel) and the 3D particle counter (Figure 10b, right panel). Strong fluorescent droplets were observed from clinical isolate 7 (Figure 10b, upper panel), but there were no strong fluorescent droplets monitored with isolate 1 (Figure 10b, lower panel) when droplets were analyzed with a fluorescence microscope or 3D particle counter. The signal spikes shown in Figure 10b are voltage signals converted from fluorescence emissions by the PMT and the trans-impedance amplifier (TIA) in the IC 3D. The voltage spike profile in the time domain (Figure 1, left corner panel) was extracted and checked by the fitting software developed by Dr. Gratton (Laboratory for Fluorescence Dynamics, UC-Irvine, USA) [28,29]. The cuvette rotation speed and the sampling rate of the ADC are adjustable, but once the system was calibrated with the sample being used, these parameters were not changed during the experiments.

The counts from IC 3D matches with the plate count very well in the range of 100-10,000. Based on the data shown in Figure 10c, the detection limit of the IC 3D system is around 10 bacteria, which means 10 fluorescent droplets could be detected in $1 \mathrm{~mL}$ droplets. In this study, $1 \mathrm{~mL}$ samples containing 10 bacteria were converted into $60 \mu \mathrm{m}$ droplets in diameter (approximately $110 \mathrm{pL}$ in volume) using microfluidic device, which means there are 9 million droplets after microencapsulation and only 10 droplets contain a single bacterium each. In our previous report, it is possible to accurately quantify $5-10$ fluorescent droplets $[25,26]$, and a similar detection limit was achieved here for the monitoring of $\beta$-lactamase-producing bacteria. However, we also observed that the false-positive count was also increased when the number of bacteria was increased in a sample because the number of empty droplets have a higher chance of contacting bacteria-containing droplets, and $\beta$-lactamase can be 
transmitted into empty droplets thorough the contacting membrane between droplets. The other possibility can be the crosstalk between droplets by small broken droplets that can transfer $\beta$-lactamase into empty droplets, causing a false-positive count. To minimize the false-positive count, we also tested the effect of bacteria cultivation within droplets, and it was observed that the detected number of bacteria was higher than the theoretical number of bacteria when droplet-encapsulated bacteria were cultivated for more than $120 \mathrm{~min}$ (Figure 10d). This result suggests that 2-h incubation will be the optimum condition to minimize the false-positive count for the quantification of bacteria.

\section{Discussion}

In this study, $\beta$-lactamase-producing bacteria were detected using commercial Fluorocillin sensors in microfluidic droplets. The limit of detection was pushed to the single-digit level within less than $5 \mathrm{~h}$. The comprehensive 3D particle counter was able to scan through the cuvette and report the positive counts in a few minutes, which reduces the sample-to-result turnaround time to less than $6 \mathrm{~h}$. The single-bacterium detection in droplets took a longer time than the microplate bulk study due to the in-droplet culturing process. However, the detection sensitivity in droplets is 1000 -fold stronger than the bulk reactor/detector. The sensors were commercially available, and the microfluidic chips are easy to make in a chemical fume hood. The 3D particle counter has been proved effective for detecting fluorescent particles, droplets, and cells rapidly. This study further demonstrated the capability of detecting a single bacterium from a low-concentration liquid sample.

Droplet generation was reproducible, and droplet stability was consistent throughout all the experiments. This was one of the benefits of using phenotypical droplet bacteria culture compared to droplet digital PCR thermal cycling, which may break a considerable number of droplets during thermocycling. Droplets were very stable at $37^{\circ} \mathrm{C}$. For milliliter-scale clinical samples, high-throughput microfluidic chips should be used not just for rapid encapsulation times, but also to avoid $\beta$-lactamase produced by the bacteria from reacting with the Fluorocillin in the syringe before they reach the nozzle of the microfluidic chips and are encapsulated in droplets, which may raise the background fluorescence of droplets that do not contain any bacteria.

Leaking is one of the weaknesses in droplet-based experiments because the sample concentration can be diluted, and it also causes contamination between droplets. It usually happens by droplet crosstalk because small molecules can be transmitted through the membrane barrier between droplets when droplets come into contact [30]. Broken tiny droplets also can transfer samples between droplets. In this study, a false-positive count was observed because of droplet crosstalk and broken droplets. To minimize this issue, droplet stability has to be guaranteed, and one potential approach can be the use of powerful surfactants that minimize the inter-droplet transfer of small molecules between droplets.

Basically, an IC 3D system was designed to detect and quantify a small number of biological markers (nucleic acid, bacteria and cancer cells) from a relatively large volume of samples (100-1000 $\mu \mathrm{L}$ ) [26]. Whole samples (1-2 $\mathrm{mL}$ ) can be encapsulated within picoliter-sized droplets in $30 \mathrm{~min}$ for analyzing the converted droplets in $10 \mathrm{~min}$. If the sample volume is less than $1 \mathrm{~mL}$, it has to be diluted with a reaction buffer so they can provide similar background intensity to that of an empty droplet. This could be one of the weakness of the current IC 3D system, but this can be solved by reducing the analyzing cuvette size that has same height but a thinner width, so it can only contain a small amount of droplets $(50-100 \mu \mathrm{L})$.

Using microfluidic droplet cultures instead of microwells can reduce the reaction volume by more than 1,000,000 times and increase the effective concentration of cells for each reaction in a single picoliter-sized droplet. Therefore, the signal-to-background ratio from each reaction was boosted to a detectable level by the PMT in a short period. In this study, both engineered and clinical drug-resistant bacteria were used; however, there are many other $\beta$-lactamase-producing bacteria that were not tested in this study. In future studies, the Fluorocillin sensors should be tested with a wider spectrum of $\beta$-lactamases in both microwells and droplets and using different liquid biopsies, such as in blood or sputum, to further validate the effectiveness of the IC 3D technology. 
Supplementary Materials: The following are available online at http://www.mdpi.com/1424-8220/20/17/4667/s1, Video S1: Droplet Single Colony.

Author Contributions: Conceptualization, W.Z. and D.K.; Methodology, W.Z. and D.-K.K.; Validation, Y.L., H.C., L.L. and D.-K.K.; Formal analysis, D.-K.K.; Investigation, W.Z. and D.-K.K.; Resources, W.Z. Writing-original draft preparation, Y.L. and D.-K.K.; Writing-review and editing, Y.L., H.C., L.L. and D.-K.K.; Visualization, D.-K.K.; Supervision, W.Z.; Project administration, W.Z.; Funding acquisition, W.Z. and D.-K.K. All authors have read and agreed to the published version of the manuscript.

Funding: This work was supported by NIH/NIAID (1 R01 AI117061) and National Research Foundation of Korea (NRF) (NRF2016R1A5A1010148 and NRF-2017R1A6A1A06015181).

Acknowledgments: We also thank Ellena Peterson who provided clinically-isolated bacteria from the UC Irvine Pathology Research Biorepository.

Conflicts of Interest: Weian Zhao and Dong-Ku Kang are founders and shareholders of Velox Biosystems, Inc., a University of California spin-off company that aims to develop rapid and sensitive diagnostic technologies. The remaining authors declare no conflict of interest.

\section{References}

1. Rudd, E.K.; Johnson, S.C.; Agesa, K.M.; Shackelford, K.A.; Tsoi, D.; Kievlan, D.R.; Colombara, D.V.; Ikuta, K.S.; Kissoon, N.; Finfer, S.; et al. Global, regional, and national sepsis incidence and mortality, 1990-2017: Analysis for the global burden of disease study. Lancet 2020, 395, 200-211. [CrossRef]

2. Paoli, C.J.; Reynolds, M.A.; Sinha, M.; Gitlin, M.; Crouser, E. Epidemiology and costs of sepsis in the United States-An analysis based on timing of diagnosis and severity level. Crit. Care Med. 2018, 46, 1889-1897. [CrossRef]

3. Sinha, M.; Jupe, J.; Mack, H.; Coleman, T.P.; Lawrence, S.M.; Fraley, S.I. Emerging technologies for molecular diagnosis of sepsis. Clin. Microbiol. Rev. 2018, 31, e00089-17. [CrossRef]

4. Levy, M.M.; Evans, L.E.; Rhodes, A. The surviving sepsis campaign bundle: 2018 update. Intensiv. Care Med. 2018, 44, 925-928. [CrossRef]

5. Reinhart, K.; Machado, F.R.; Schachter, R.D.; Daniels, R.; Kissoon, N.; Finfer, S. Recognizing sepsis as a global health priority-A WHO resolution. N. Engl. J. Med. 2017, 377, 414-417. [CrossRef]

6. Buehler, S.S.; Madison, B.; Snyder, S.R.; Derzon, J.H.; Cornish, N.E.; Saubolle, M.A.; Weissfeld, A.S.; Weinstein, M.P.; Liebow, E.B.; Wolk, D.M. Effectiveness of practices to increase timeliness of providing targeted therapy for inpatients with bloodstream infections: A laboratory medicine best practices systematic review and meta-analysis. Clin. Microbiol. Rev. 2015, 29, 59-103. [CrossRef]

7. Fauci, A.S.; Marston, H.D. The perpetual challenge of antimicrobial resistance. JAMA 2014, 311, $1853-1854$. [CrossRef]

8. Pradipta, I.S.; Sodik, D.C.; Lestari, K.; Parwati, I.; Halimah, E.; Diantini, A.; Abdulah, R. Antibiotic resistance in sepsis patients: Evaluation and recommendation of antibiotic use. N. Am. J. Med. Sci. 2013, 5, 344-352. [CrossRef]

9. Giraldez, M.D.; Chevillet, J.R.; Tewari, M. Droplet digital PCR for absolute quantification of extracellular MicroRNAs in plasma and serum: Quantification of the cancer biomarker hsa-miR-141. In Advanced Structural Safety Studies; Springer Protocols: New York City, NY, USA, 2018; pp. 459-474.

10. Gobert, G.; Cotillard, A.; Fourmestraux, C.; Pruvost, L.; Miguet, J.; Boyer, M. Droplet digital PCR improves absolute quantification of viable lactic acid bacteria in faecal samples. J. Microbiol. Methods 2018, 148, 64-73. [CrossRef]

11. Pacocha, N.; Scheler, O.; Nowak, M.M.; Derzsi, L.; Cichy, J.; Garstecki, P. Direct droplet digital PCR (dddPCR) for species specific, accurate and precise quantification of bacteria in mixed samples. Anal. Methods 2019, 11, 5730-5735. [CrossRef]

12. Collins, D.J.; Neild, A.; Demello, A.; Liu, A.Q.; Ai, Y. The Poisson distribution and beyond: Methods for microfluidic droplet production and single cell encapsulation. Lab. Chip 2015, 15, 3439-3459. [CrossRef] [PubMed]

13. Kaminski, T.; Garstecki, P. Controlled droplet microfluidic systems for multistep chemical and biological assays. Chem. Soc. Rev. 2017, 46, 6210-6226. [CrossRef] [PubMed] 
14. Chantemesse, B.; Betelli, L.; Solanas, S.; Vienney, F.; Bollache, L.; Hartmann, A.; Rochelet-Dequaire, M. A nitrocefin-based amperometric assay for the rapid quantification of extended-spectrum $\beta$-lactamase-producing Escherichia coli in wastewaters. Water Res. 2017, 109, 375-381. [CrossRef] [PubMed]

15. Kim, S.; Masum, F.; Jeon, J.S. Recent developments of chip-based phenotypic antibiotic susceptibility testing. BioChip J. 2019, 13, 43-52. [CrossRef]

16. Bush, K.; Bradford, P.A. $\beta$-Lactams and $\beta$-Lactamase inhibitors: An overview. Cold Spring Harb. Perspect. Med. 2016, 6, a025247. [CrossRef]

17. Bush, K. Past and present perspectives on $\beta$-lactamases. Antimicrob. Agents Chemother. 2018, 62. [CrossRef]

18. Legesse, M.H.; Weldearegay, G.M.; Asrat, D. Extended-spectrum beta-lactamase- and carbapenemase-producing Enterobacteriaceae among Ethiopian children. Infect. Drug Resist. 2017, 10, $27-34$. [CrossRef]

19. Kunishima, H.; Ishibashi, N.; Wada, K.; Oka, K.; Takahashi, M.; Yamasaki, Y.; Aoyagi, T.; Takemura, H.; Kitagawa, M.; Kaku, M. The effect of gut microbiota and probiotic organisms on the properties of extended spectrum beta-lactamase producing and carbapenem resistant Enterobacteriaceae including growth, beta-lactamase activity and gene transmissibility. J. Infect. Chemother. 2019, 25, 894-900. [CrossRef]

20. Bar-Yoseph, H.; Hussein, K.; Braun, E.; Paul, M. Natural history and decolonization strategies for ESBL/carbapenem-resistant Enterobacteriaceae carriage: Systematic review and meta-analysis. J. Antimicrob. Chemother. 2016, 71, 2729-2739. [CrossRef]

21. Lean, S.S.; Suhaili, Z.; Ismail, S.; Rahman, N.I.A.; Othman, N.; Abdullah, F.H.; Jusoh, Z.; Yeo, C.C.; Thong, K.L. Prevalence and genetic characterization of carbapenem - and polymyxin-resistant acinetobacter baumannii isolated from a tertiary hospital in Terengganu, Malaysia. ISRN Microbiol. 2014, 2014, 1-9. [CrossRef]

22. Dopirak, M.; Hill, C.; Oleksiw, M.; Dumigan, D.; Arvai, J.; English, E.; Carusillo, E.; Malo-Schlegel, S.; Richo, J.; Traficanti, K.; et al. Surveillance of hemodialysis-associated primary bloodstream infections: The experience of ten hospital-based centers. Infect. Control. Hosp. Epidemiol. 2002, 23, 721-724. [CrossRef] [PubMed]

23. Abram, T.J.; Cherukury, H.; Ou, C.Y.; Vu, T.; Toledano, M.; Li, Y.; Grunwald, J.T.; Toosky, M.N.; Tifrea, D.F.; Slepenkin, A.; et al. Rapid bacterial detection and antibiotic susceptibility testing in whole blood using one-step, high throughput blood digital PCR. Lab. Chip 2019, 20, 477-489. [CrossRef] [PubMed]

24. Ou, C.Y.; Vu, T.; Grunwald, J.T.; Toledano, M.; Zimak, J.; Toosky, M.; Shen, B.; Zell, J.A.; Gratton, E.; Abram, T.J.; et al. An ultrasensitive test for profiling circulating tumor DNA using integrated comprehensive droplet digital detection. Lab. Chip 2019, 19, 993-1005. [CrossRef] [PubMed]

25. Zhang, K.; Kang, N.K.; Ali, M.M.; Liu, L.; Labanieh, L.; Lu, M.; Riazifar, H.; Nguyen, T.N.; Zell, J.A.; Digman, M.A.; et al. Digital quantification of miRNA directly in plasma using integrated comprehensive droplet digital detection. Lab. Chip 2015, 15, 4217-4226. [CrossRef]

26. Kang, N.K.; Ali, M.M.; Zhang, K.; Huang, S.S.; Peterson, E.; Digman, M.A.; Gratton, E.; Zhao, W. Rapid detection of single bacteria in unprocessed blood using integrated comprehensive droplet digital detection. Nat. Commun. 2014, 5, 5427. [CrossRef]

27. Chen, C.H.; Sarkar, A.; Song, Y.A.; Miller, M.A.; Kim, S.J.; Griffith, L.G.; Lauffenburger, D.A.; Han, J. Enhancing protease activity assay in droplet-based microfluidics using a biomolecule concentrator. J. Am. Chem. Soc. 2011, 133, 10368-10371. [CrossRef]

28. Skinner, J.P.; Swift, K.M.; Ruan, Q.; Perfetto, S.; Gratton, E.; Tetin, S.Y. Simplified confocal microscope for counting particles at low concentrations. Rev. Sci. Instrum. 2013, 84, 074301. [CrossRef]

29. Altamore, I.; Lanzano, L.; Gratton, E. Dual channel detection of ultra low concentration of bacteria in real time by scanning fluorescence correlation spectroscopy. Meas. Sci. Technol. 2013, 24, 065702. [CrossRef]

30. Chowdhury, M.S.; Zheng, W.; Kumari, S.; Heyman, J.A.; Zhang, X.C.; Dey, P.; Weitz, D.A.; Haag, R. Dendronized fluorosurfactant for highly stable water-in-fluorinated oil emulsions with minimal inter-droplet transfer of small molecules. Nat. Commun. 2019, 10, 4546. [CrossRef]

(C) 2020 by the authors. Licensee MDPI, Basel, Switzerland. This article is an open access article distributed under the terms and conditions of the Creative Commons Attribution (CC BY) license (http://creativecommons.org/licenses/by/4.0/). 